\title{
Oral Liquid Formulation of Etravirine for Enhanced Bioavailability
}

\section{Jyothy John and Dong Liang*}

Department of Pharmaceutical Sciences, College of Pharmacy and Health Sciences, Texas Southern University, 3100 Cleburne Street, Houston, TX 77004, USA

\begin{abstract}
Aim: Etravirine is the first drug in the second generation of Non-Nucleoside Reverse Transcriptase Inhibitors (NNRTIs). Despite its use in clinical management of HIV infected patients, the drug has very limited bioavailability due to low water solubility and low gastrointestinal permeability. The majority of currently available anti-AIDS drugs in the U.S. market are in solid dosage forms. There is a need of introducing an oral liquid dosage formulation, especially for those AIDS patients who are often unable to swallow a pill.
\end{abstract}

Methods: Co-solvent formulations of etravirine were prepared using 1-methyl-2-pyrrolidinone, Labrasol, and water after evaluating the etravirine solubility in various solvents. A long term stability study was carried out to examine the physical stability of an optimal oral formulation of etravirine. Pharmacokinetic studiesof etravirine were conducted in rats to evaluate bioavailability of the drug. Four groups of jugular vein-cannulated male SpragueDawley rats were orally administered etravirine dosage forms such asetravirine solution in DMSO $(2.5 \mathrm{mg} / \mathrm{kg})$, commercial etravirine tablets $(200 \mathrm{mg} / \mathrm{kg}$ ), and an optimized liquid formulation $(25 \mathrm{mg} / \mathrm{kg}$ and $50 \mathrm{mg} / \mathrm{kg}$ ), respectively. Serial blood samples were collected at predetermined time points. Plasma samples were analyzed for etravirine concentration using a validated LC-MS/MS assay. Pharmacokinetic and statistical data analysis was performed using WinNonlin and Systat.

Results: A co-solvent dosage formulation of etravirine was developed containing $5 \mathrm{mg} / \mathrm{mL}$ of etravirine dissolved in 3.5\% 1-methyle 2-pyrrolidinone, $46.5 \% \mathrm{Labrasol}$, and $50 \%$ water. The formulation was found to be stable after 21 months storage at room temperature. The drug formulation was successfully administered to rats without any signs of acute toxicity. Pharmacokinetic study showed over 40 -times superior oral bioavailability of the formulation as compared with the marketed Intelence ${ }^{\circledR}$ Tablet formulation.

Conclusion: A stable co-solvent liquid solution formulation of etravirine was developed with significantly improved oral bioavailability for potential clinical application.

Keywords: Etravirine; Bioavailability; Liquid formulation

Abbreviations: NNRTI: Non-Nucleoside Reverse Transcriptase Inhibitors; IS: Internal Standard; NMP: 1-methyl 2-pyrrolidinone; HPLC: High Performance Liquid Chromatography; LC-MS/MS: Liquid Chromatographic-Tandem Mass Spectrometry; DMSO: Dimethyl Sulfoxide

\section{Introduction}

Etravirine is the first drug in the second generation of NonNucleoside Reverse Transcriptase Inhibitors (NNRTIs) and has been recently marketed for the treatment of HIV infection [1]. Etravirine is more abundant than other first generation NNRTIs due to its activity against NNRTI-resistant HIV-1 [2]. The recommended dose of this drug is $200 \mathrm{mg}$ (two $100 \mathrm{mg}$ tablets) taken twice daily following a meal [3]. Etravirine is highly bound to plasma proteins and is primarily metabolized by cytochrome P450 CYP 3A4, 2C9, and 2C19 enzymes. This highly lipophilic drug contains an octanol: water partition coefficient $(\log \mathrm{P})$ greater than 5 along with an ionization constant (pka) of 3.75 [4]. Despite its use in the clinical management of HIV infected patients, limited pharmacokinetic information is available regarding the absorption, distribution, metabolism, and excretion following oral administration [5].

Based on in vitro experiments, etravirine is thought to be absorbed via a passive Trans cellular diffusion mechanism. Moreover, etravirine is an inhibitor of p-glycoprotein with an apparent $\mathrm{IC}_{50}$ value of 24.2 $\mu \mathrm{M}$. Etravirine is absorbed slowly, with median peak concentration occurring at approximately 4 hours (2 to 6 hours depending on the formulation) after fasted oral administration (Figure 1). The absolute oral bioavailability of etravirine has not been determined because of the lack of an intravenous formulation [6]. In vivo, etravirine is an inducer of CYP3A4 and an inhibitor of the CYP2C subfamily [7]. Etravirine has a terminal elimination half-life in plasma of approximately 30 40 hours. The drug should be taken following a meal to enhance bioavailability [8]. Etravirine has low solubility and low gastrointestinal permeability, and is categorized as a Class IV compound according to the Biopharmaceutics Classification System [9].

Currently, themajority of marketed anti-AIDS are solid dosage forms and there is a need for a liquid formulation for better patient compliance especially for those who have difficulty in swallow tablets or capsules. We have developed a water soluble and stable etravirine liquid solution formulation suitable for oral administration. Oral bioavailability of the formulation was also compared with the commercial Intelence ${ }^{\circledR} 100 \mathrm{mg}$ Tablets.

*Corresponding author: Dong Liang, Department of Pharmaceutical Sciences College of Pharmacy and Health Sciences, Texas Southern University, 3100 Cleburne Street, Houston, TX 77004, USA, Tel: 713-313-1885; Fax: 713-3131091; E-mail: liang_dx@tsu.edu

Received June 25, 2013; Accepted February 24, 2014; Published March 04 2014

Citation: John J, Liang D (2014) Oral Liquid Formulation of Etravirine for Enhanced Bioavailability. J Bioequiv Availab 6: 046-052. doi:10.4172/jbb.1000179

Copyright: (c) 2014 John J, et al. This is an open-access article distributed under the terms of the Creative Commons Attribution License, which permits unrestricted use, distribution, and reproduction in any medium, provided the original author and source are credited. 


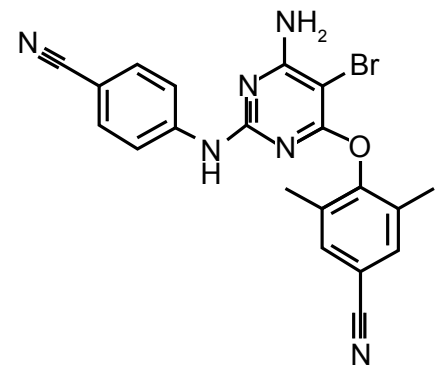

Figure 1: Chemical structure of etravirine.

\section{Materials and Methods}

\section{Chemicals and reagents}

Etravirine standard powder (98\% pure, Lot\# 10-ABY-54, $\mathrm{MW}=435.28)$ was purchased from Toronto Research Chemicals Inc. (Ontario, Canada). Intelence ${ }^{\circledR} 100 \mathrm{mg}$ Tablet (Tibotec Therapeutics, Titusville, NJ) were obtained from a local CVS pharmacy. Itraconazole, formic acid, ammonium acetate and 1-methyle 2- pyrrolidinone (Lot\# 00796TK), mineral oil, paraffin oil, soybean oil, peanut oil, olive oil, Tween 80 (Lot\# 049 K0041) were purchased from Sigma (St. Louis, MO). HPLC grade methanol (Mallinckrodt Baker Inc., Phillipsburg, $\mathrm{NJ}$ ), acetonitrile (VWR International LLC, West Chester, PA), Labrasol (Gattffossesas, Cedex, France), DMSO (Lot\# 46081638), phosphoric acid (EMD Chemicals Inc., Gibbstown, NJ), PEG 400 (Wood Scientific Inc., Lot\# 960610), peppermint oil and lavender oil (Spectrum Chemical MFG, Corp., Gardena, CA) were purchased from the respective manufacturers and coriander oil and Tween 20 (Lot\# 85977) were purchased from PCCA (Houston, TX). De-ionized water was obtained using a Milli-Q analytical deionization system (Millipore, Bedford, MA). Freshly obtained drug-free rat plasma was collected from adult male Sprague-Dawley rats in our laboratory and stored at $-80^{\circ} \mathrm{C}$ prior to use. All other chemicals and solvents were of reagent grade and used without further purification.

\section{Evaluation of etravirine solubility in various media}

The solubility of etravirine was determined in water, various oils and selected organic solvents by phase solubility analysis. Briefly, excess amount of etravirine powder was added to $20 \mathrm{~mL}$ screw-capped scintillation vials each containing $5 \mathrm{~mL}$ of a test solvent. The vials were rotated end-over-end at a constant speed on a shaker (EBERBACH Corporation, Ann Arbor, MI) at room temperature for 3 days (72 hours). Then the samples were subjected to centrifugation on a laboratory centrifuge at $13,000 \mathrm{rpm}$ for 15 minutes. Clear supernatant was transferred to another micro centrifuge tube, and diluted with DMSO to the proper concentration before they were analyzed for etravirine concentration using an established HPLC method.

\section{Analysis of etravirine using HPLC method}

The high-performance liquid chromatographic system used Waters 600 pump, 2487 UV detector and 717 plus auto sampler (Milford, MA). Separations were done on a $4.6 \times 150 \mathrm{~mm}, 3.5 \mu \mathrm{m}$ XTerra MS$\mathrm{C}_{18}$ column (Milford, MA). The flow rate was set at $1 \mathrm{~mL} / \mathrm{min}$ by isocratic method and the analytes were monitored at a wavelength of $304 \mathrm{~nm}$. Chromatographic data acquisition, peak integration and quantification were performed using the Empower software package by Waters Corporation. The mobile phase consisted of $20 \mathrm{mM}$ potassium dihydrogen phosphate aqueous solution (40\%) and acetonitrile (60\%).
The $\mathrm{pH}$ was adjusted to 3.2 using phosphoric acid. Solvents were regularly prepared prior to each series of analysis.

A stock solution of the Internal Standard (I.S.) itraconazole at 1 $\mathrm{mg} / \mathrm{mL}$ (in acetonitrile) was diluted to obtain a working solution of $25 \mu \mathrm{g} / \mathrm{mL}$. A stock solution of etravirine in DMSO $(1 \mathrm{mg} / \mathrm{mL})$ was diluted with the mobile phase for the preparation of working solutions at concentrations ranging from $1 \mu \mathrm{g} / \mathrm{mL}$ to $100 \mu \mathrm{g} / \mathrm{mL}$. These working solutions were diluted 1:10 with blank plasma to obtain the calibration standards ranging from $0.1 \mu \mathrm{g} / \mathrm{mL}$ to $10 \mu \mathrm{g} / \mathrm{mL}$.

\section{Formulation development}

Co-solvent formulations of etravirine were prepared by dissolving etravirine powder in small quantity of1-methyl 2-pyrrolidinone (NMP). Surfactants such as Labrasol (caprylocaproyl macrogol-8 glyceride) were added followed by purified water. Various solvent compositions were evaluated to determine the optimal co-solvent system. Each formulation was immediately tested for precipitation potential by $1: 10$ dilution of the formulation with purified water. Optimal formulations with no precipitation upon room temperature storageconditions for 21 months were further analyzed on etravirine stability in the formulation.

\section{Stability of the etravirine formulation}

A long-term stability study was carried out to examine the physical and chemical stability of an optimal oral formulation of etravirine (Formulation \# 59). Three batches of Formulation \# 59 were prepared, and stored at room temperature. Etravirine concentrations in each batch were measured by HPLC on the day of preparation and followed up to 21 months.

\section{Animal studies}

All animal experiments and protocols were reviewed and approved by the Institutional Animal Care and Use Committee. Adult male Sprague-Dawley rats (250-350 g, Harlan Sprague Dawley, Inc., Indianapolis, IN) were housed in stainless steel cages and had free access to food and water. They were acclimated to the animal care facility for at least 7 days before the start of the study. To facilitate the withdrawal of timed, multiple blood samples from each animal, the right jugular vein of each animal was cannulated one day prior to drug administration. The cannulas were flushed daily with $0.5 \mathrm{~mL}$ sterile heparinizedsaline (100 units $/ \mathrm{mL})$. Under ketamine:acetopromazin e:xylazine (50:3.3:3.3 mg/kg ip) anesthesia, silicone elastomer tubing $(0.02 \times 0.037 \mathrm{in})$ was inserted into the jugular vein, secured with a silk suture, and exteriorized in the dorsal infrascapular area. The surgical incision were prophylactically treated with nitrofurazone wound powder and closed with surgical staples.

All in vivo studies were initiated between 8:00 am and 9:00 am to eliminate possible circadian variation.The animals were fasted overnight with water allowed ad libitum before oral dosing. The in vivo study consisted of four groups of rats. Group $1(\mathrm{n}=6)$, was given an intravenous $2.5 \mathrm{mg} / \mathrm{kg}$ administration of etravirine solution (3.5 $\mathrm{mg} / \mathrm{mL}$ dissolved in DMSO). Group 2, a reference group $(\mathrm{n}=5)$ was given an oral $200 \mathrm{mg} / \mathrm{kg}$ dose of a suspension of Intelence ${ }^{\circledR}$ tablets in $1 \%$ Tween 80 . Group $3(n=8)$ received Formulation \# 59 by an oral dose of $25 \mathrm{mg} / \mathrm{kg}$ etravirine. Group $4(\mathrm{n}=8)$ also received Formulation \# 59 orallybut at a dose of $50 \mathrm{mg} / \mathrm{kg}$ etravirine. Oral administration was performed using an animal feeding needle (18 in. $\times 3$ in. W; 2-1/4 $\mathrm{mm}$ Ball). The etravirine dose was explored in our laboratory prior to the current study. The marketed etravirine (Intelence ${ }^{\circledR}$ ) has very low 
oral bioavailability, thus $200 \mathrm{mg} / \mathrm{kg}$ PO dose was used in order to obtain detectable plasma levels. Much lower doses $(25 \mathrm{mg} / \mathrm{kg}$ and 50 $\mathrm{mg} / \mathrm{kg} \mathrm{PO}$ ) were used for our formulation with significantly increased bioavailability. An even lower dose of $2.5 \mathrm{mg} / \mathrm{kg}$ was used in the intravenous group so that plasma levels would be comparable with the oral dosing groups. In addition, the plasma concentrations observed in our formulation were comparable to clinical $\mathrm{C}_{\max }$ levels of around 800 $\mathrm{ng} / \mathrm{mL}[10]$. Following the drug administration, blood samples $(0.25$ $\mathrm{mL}$ ) were collected (from the jugular vein cannula) immediately before dosing and at $0.5,1,1.5,2,3,4,5,6,8,10$ and 24 hours after dosing. Plasma samples were isolated, stored at $-80^{\circ} \mathrm{C}$ and analyzed within 2 weeks using LC-MS/MS method.

\section{LC-MS/MS determination of etravirine concentrations in rat plasma}

Etravirine concentrations in rat plasma were analyzed using a sensitive and accurate Liquid Chromatographic-Tandem Mass Spectrometry (LC-MS/MS) method developed in this laboratory [11]. Etravirine and the internal standard (itraconazole) were separated on a reverse phase XTerra MS- $\mathrm{C}_{18}$ column $(50 \times 2.1 \mathrm{~mm}, 3.5 \mu \mathrm{m})$ in conjunction with an $\mathrm{XTerra}^{\circledR} \mathrm{MS} \mathrm{C}_{18}$ guard column $(20 \times 3.9 \mathrm{~mm}, 3.5$ $\mu \mathrm{m})$. The mobile phase consisted of a $2 \mathrm{mM}$ ammonium acetate aqueous solution containing $0.1 \%$ formic acid aqueous solution (Mobile Phase A) and a $0.1 \%$ formic acid in methanol solution (Mobile Phase B). The gradient elution for mobile phase B was as follows: $40 \%$ to $100 \%$ in 5 min kept constant for $2 \mathrm{~min}$ and then decreased to $40 \%$ in $0.1 \mathrm{~min}$ and this composition was maintained until the end of the run $(8.0 \mathrm{~min})$. The flow rate was set at $0.3 \mathrm{~mL} / \mathrm{min}$. The column elutewas monitored using a 3200 QTRAP ${ }^{\circledR}$ LC-MS/MS, which is a hybrid triple quadruple linear ion trap equipped with a turbolonspray ion source. Pure nitrogen was generated by a Parker Balston Source 5000 Tri Gas Generator. The Ion Spray heater was maintained at $650^{\circ} \mathrm{C}$ with both the nebulizer gas and heater gas set to $80 \mathrm{psi}$. Ion Spray needle voltage was set to $4500 \mathrm{~V}$, the curtain gas was set to $10 \mathrm{psi}$, and the collision CAD gas was set to medium.

A series of etravirine working standard solutions were prepared by appropriate dilutions of the stock etravirine standard solution $(1 \mathrm{mg} /$ $\mathrm{mL})$ with a methanol:water solution (50:50, v/v). Plasma samples are spiked with $20 \mu \mathrm{L}$ of etravirine standard solution to yield calibration standards in plasma over the concentration range of $1-100 \mathrm{ng} / \mathrm{mL}$. Etravirine was extracted from plasma samples before the LC-MS/MS assay. Briefly, an aliquot $(100 \mu \mathrm{L})$ of plasma sample was mixed with $500 \mu \mathrm{L}$ of ethyl acetate containing $200 \mathrm{ng} / \mathrm{mL}$ of the internal standard. The mixture was vortexed for 30 seconds, and centrifuged for $20 \mathrm{~min}$. Then $450 \mu \mathrm{L}$ of the supernatant was air dried, and the residual was reconstituted with $50 \%$ methanol in water, vortexed again, centrifuged and the supernatant was injected onto the LC-MS/MS system for quantification.

\section{Pharmacokinetic and statistical data analysis}

Non-compartmental pharmacokinetic parameters were determined by classical techniques using the WinNonlin computer program. The maximum plasma concentration of drug $\left(\mathrm{C}_{\max }\right)$ was determined from the plasma drug concentration versus time profile. The terminal elimination half-life $\left(t_{1 / 2}\right)$ was determined from the slope of the terminal linear segment of a semi logarithmic plot of plasma drug concentration vs. time. The total area under the plasma concentration-time curve (AUC) was determined by the trapezoidal rule using plasma drug concentration vs. time data from time zero to the last experimental time plus the extrapolated area (from the last experimental time to time infinity). The extrapolated area was calculated as $1.44 \times \mathrm{t}_{1 / 2} \times$ plasma concentration at the last experimental time. The systemic clearance (CL) was determined as Dose/AUC. The volume of distribution at steady-state $\left(\mathrm{V}_{\mathrm{ss}}\right)$ was calculated as Dose/ [AUMC/AUC ${ }^{2}$, where AUMC is the area under the first moment plasma concentration time curve.

AUMC is calculated using the equation:

$$
\mathrm{AUMC}=\int_{0}^{\mathrm{T}} \mathrm{t} . \mathrm{Cp} . \mathrm{dt}+\frac{\mathrm{TCp} *}{\lambda \mathrm{z}}+\frac{\mathrm{Cp} *}{(\lambda \mathrm{z})^{2}}
$$

Where $\lambda z=$ terminal slope of the plasma con. versus time curve

$\mathrm{Cp}^{*}=$ last measured plasma concentration

$\mathrm{T}=$ last measured time value

$\mathrm{t}=$ time

Absolute bioavailability $\left(\mathrm{F}_{\text {absolute }}\right)$ was calculated using $\left[\left(\right.\right.$ AUC $_{\text {oral }} \times$ Dose $\left._{\text {i. }}\right) /\left(\right.$ AUC $_{\text {i.v }} \times$ Dose $\left.\left._{\text {oral }}\right)\right] \times 100 \%$. Relative bioavailability was calculated using the equation [ $\left(\mathrm{AUC}_{\text {formulation }} \times\right.$ Dose $\left._{\text {reference }}\right) /\left(\right.$ Dose $_{\text {for }}$ mulation $\left.\left.\times \mathrm{AUC}_{\text {reference }}\right)\right] \times 100 \%$.

Statistical differences between the mean pharmacokinetic values were determined by Student $t$-test. The statistical analysis wasperformed in SYSTAT version 12.0 computer programs. A p-value of less than 0.05 was considered as statistically significant.

\section{Results}

\section{Development of oral formulation of etravirine}

Etravirine has low solubility in the tested oils and aqueous media (Table 1). The solubility of etravirine in distilled water is $3.9 \mu \mathrm{g} / \mathrm{mL}$. We found the drug is more soluble in NMP $(458 \mathrm{mg} / \mathrm{mL})$ and Labrasol $(61 \mathrm{mg} / \mathrm{mL})$. Various compositions of surfactantand co-surfactant were evaluated for an optimal oral formulation of etravirine. Table 2 summarizes the compositions of the various etravirine formulations. Etravirine concentrations in these formulations ranged from $5 \mathrm{mg} /$ $\mathrm{mL}$ to $10 \mathrm{mg} / \mathrm{mL}$. Most ofthese formulations were clear solutions

\begin{tabular}{|l|c|}
\hline Vehicle & Drug Solubility $\mathbf{( m g / m L})$ \\
\hline Water & 0.00397 \\
\hline PEG 400 & $71.6 \pm 1.45$ \\
\hline 1- methyl- 2-pyrrolidinone & 458.4 \\
\hline Labrasole & 61.0 \\
\hline Tween 80 & $49.7 \pm 0.41$ \\
\hline Tween 20 & $55.8 \pm 0.87$ \\
\hline Cremophore EL & $46.0 \pm 0.69$ \\
\hline Plurooleique CC 497 & $1.04 \pm 0.02$ \\
\hline Labrafac CC & $1.04 \pm 0.01$ \\
\hline Caproyl 90 & $5.42 \pm 0.06$ \\
\hline Peanut Oil & 2.19 \\
\hline Paraffin Oil & 0.009 \\
\hline Linseed Oil & 0.79 \\
\hline Lavender Oil & 1.23 \\
\hline Corn Oil & 0.42 \\
\hline Mineral Oil & 0.004 \\
\hline Soybean Oil & 0.31 \\
\hline Olive Oil & 0.22 \\
\hline Coriander Oil & 0.74 \\
\hline
\end{tabular}

Table 1: Solubility of etravirine in various medium at room temperature. 
Citation: John J, Liang D (2014) Oral Liquid Formulation of Etravirine for Enhanced Bioavailability. J Bioequiv Availab 6: 046-052. doi:10.4172/ jbb.1000179

initially followed by the drug precipitation within 24 hours at room temperature.

The co-solvent system (Formulation \#59) consisting NMP, Labrasol, and water at 3.5:46.5:50 (v/v/v) ratio showed a $5 \mathrm{mg} / \mathrm{mL}$ drug solubility in $50 \%$ of an aqueous medium, and no drug precipitation after storage. Thus, this formulation was selected forfurther long-term drug stability testing as well as in vivo bioavailability evaluations.

\section{Evaluation of formulation stability}

We evaluated etravirine stability in our dosage formulation \# 59 for long-term storage at room temperature. We found no significant degradation of etravirine from three separate batches of the formulation after 21-month storage at room temperature. Following the 21 month storage, there was also no sign of drug precipitation (Table 3 ).

\section{Pharmacokinetic studies}

In vivo pharmacokinetic studies were conducted to evaluate whether the developed oral formulation (\#59) of etravirine had comparable oral bioavailability to the proprietary $100 \mathrm{mg}$ Intelence ${ }^{\circledR}$ tablets. Figure 2 showed mean plasma concentrations versus time curve of etravirine following the drug administrations. The time to reach maximum plasma drug concentration was about 2 hours post administration for the reference group, whereas, the $\mathrm{T}_{\max }$ for Formulation \# 59 group ranged from 4-6 hours post drug administration. Mean plasma concentrations were higher in the Formulation \# 59 group as compared with the reference group.

Pharmacokinetic parameters are summarized in Table 4 and statistical comparisons are performed after dose normalization. There was an 8 -fold increase in the maximum plasma concentration $\left(\mathrm{C}_{\max }\right)$ and 5-fold increase in the Area Underthe Curve (AUC) for $25 \mathrm{mg} /$ $\mathrm{kg}$ formulation group as compared with the reference commercial Intelence $^{\circledR}$ group. The terminal elimination half-lives for orally administered groups were not significantly different from that of intravenously administered group. There was no significant difference between the $\mathrm{C}_{\max }$ of $25 \mathrm{mg} / \mathrm{kg}$ and $50 \mathrm{mg} / \mathrm{kg}$ doses of our cosolvent formulation.

The absolute oral bioavailability $\left(\mathrm{F}_{\text {absolute }}\right)$ of etravirine in the commercial Intelence ${ }^{\circledR}$ tablet was $0.13 \%$. Absolute oral bioavailability

\begin{tabular}{|c|c|c|c|c|c|c|c|c|c|c|c|c|c|c|c|}
\hline \multirow[t]{2}{*}{ Formula } & \multirow[t]{2}{*}{ Drug } & \multirow[t]{2}{*}{ DMSO } & \multirow[t]{2}{*}{ PEG 400} & \multirow[t]{2}{*}{ Tween 80} & \multirow[t]{2}{*}{ Cremophor EL } & \multirow{2}{*}{$\begin{array}{l}\text { 1-methyl-2- } \\
\text { pyrrolidones }\end{array}$} & \multirow[t]{2}{*}{ Tween 20} & \multirow[t]{2}{*}{ Labrasol } & \multirow[t]{2}{*}{ Capryol 90} & \multirow[t]{2}{*}{ Plurololeique } & \multirow[t]{2}{*}{ Labrafac } & \multirow[t]{2}{*}{ Water } & \multicolumn{3}{|c|}{ Appearance } \\
\hline & & & & & & & & & & & & & $1 \mathrm{~h}$ & $5 \mathrm{~h}$ & $24 \mathrm{~h}$ \\
\hline 1 & $10 \mathrm{mg}$ & $50 \mu \mathrm{L}$ & $450 \mu \mathrm{L}$ & & & & & & & & & $500 \mu \mathrm{L}$ & ppt & ppt & $\mathrm{ppt}^{*}$ \\
\hline 2 & $10 \mathrm{mg}$ & $50 \mu \mathrm{L}$ & & & $300 \mu \mathrm{L}$ & & & & & & & $500 \mu \mathrm{L}$ & clear & ppt & $\mathrm{ppt}$ \\
\hline 4 & $10 \mathrm{mg}$ & $50 \mu \mathrm{L}$ & & $450 \mu \mathrm{L}$ & & & & & & & & $500 \mu \mathrm{L}$ & clear & ppt & $\mathrm{ppt}$ \\
\hline 6 & $10 \mathrm{mg}$ & $50 \mu \mathrm{L}$ & & & & & $450 \mu \mathrm{L}$ & & & & & $500 \mu \mathrm{L}$ & clear & ppt & ppt \\
\hline 7 & $10 \mathrm{mg}$ & $50 \mu \mathrm{L}$ & & $300 \mu \mathrm{L}$ & & & & $150 \mu \mathrm{L}$ & & & & $500 \mu \mathrm{L}$ & clear & ppt & $\mathrm{ppt}$ \\
\hline 9 & $10 \mathrm{mg}$ & $25 \mu \mathrm{L}$ & & & & & & $380 \mu \mathrm{L}$ & & $95 \mu \mathrm{L}$ & & $500 \mu \mathrm{L}$ & clear & ppt & $\mathrm{ppt}$ \\
\hline 10 & $10 \mathrm{mg}$ & $50 \mu \mathrm{L}$ & $100 \mu \mathrm{L}$ & $350 \mu \mathrm{L}$ & & & & & & & & $500 \mu \mathrm{L}$ & clear & clear & $\mathrm{ppt}$ \\
\hline 24 & $10 \mathrm{mg}$ & & & & & & & $250 \mu \mathrm{L}$ & & & $250 \mu \mathrm{L}$ & $500 \mu \mathrm{L}$ & clear & clear & $\mathrm{ppt}$ \\
\hline 29 & $5 \mathrm{mg}$ & & & & & & & $700 \mu \mathrm{L}$ & & & & $300 \mu \mathrm{L}$ & clear & clear & clear \\
\hline 39 & $5 \mathrm{mg}$ & & & & & & & $500 \mu \mathrm{L}$ & & $70 \mu \mathrm{L}$ & $30 \mu \mathrm{L}$ & $400 \mu \mathrm{L}$ & clear & clear & $\mathrm{ppt}$ \\
\hline 45 & $10 \mathrm{mg}$ & & & & & $100 \mu \mathrm{L}$ & & $200 \mu \mathrm{L}$ & $100 \mu \mathrm{L}$ & & $100 \mu \mathrm{L}$ & $500 \mu \mathrm{L}$ & clear & clear & $\mathrm{ppt}$ \\
\hline 50 & $10 \mathrm{mg}$ & & & & & & & $400 \mu \mathrm{L}$ & $100 \mu \mathrm{L}$ & & & $400 \mu \mathrm{L}$ & clear & clear & ppt \\
\hline 58 & $5 \mathrm{mg}$ & & & & & $35 \mu \mathrm{L}$ & & $500 \mu \mathrm{L}$ & & & & $465 \mu \mathrm{L}$ & clear & clear & clear \\
\hline $59^{* *}$ & $5 \mathrm{mg}$ & & & & & $35 \mu \mathrm{L}$ & & $465 \mu \mathrm{L}$ & & & & $500 \mu \mathrm{L}$ & clear & clear & clear \\
\hline
\end{tabular}

${ }^{*}$ Precipitation

**The formulation was selected for further long-term stability and oral bioavailability test

Table 2: Compositions of selected oral etravirine liquid formulations.

Storage Time Immediately After the Preparation

1 month at room temperature

3 months at room temperature

9 months at room temperature

21 months at room temperature
Mean $\pm S D$ Etravirine Concentration $(\mathrm{mg} / \mathrm{mL})$ in the Formulation \#59

$4.922 \pm 0.044$
$5.153 \pm 0.028$
$4.978 \pm 0.097$
$5.013 \pm 0.010$
$4.977 \pm 0.474$

Table 3: Stability of etravirine in the dosage formulation $\# 59$ at room temperature.

\begin{tabular}{|c|c|c|c|c|}
\hline Parameter $^{\mathrm{a}}$ & Intravenous $2.5 \mathrm{mg} / \mathrm{kg}$ of Etravirine & Oral $200 \mathrm{mg} / \mathrm{kg}$ of Intelence ${ }^{\circledR}$ & Oral $25 \mathrm{mg} / \mathrm{kg}$ of Formulation \#59 & Oral $50 \mathrm{mg} / \mathrm{kg}$ of Formulation \#59 \\
\hline Number of Animals & 6 & 5 & 8 & 8 \\
\hline $\mathrm{C}_{\max }(\mathrm{ng} / \mathrm{mL})$ & $2364 \pm 1122$ & $27.97 \pm 11.9$ & $222.3 \pm 150$ & $228.2 \pm 169$ \\
\hline $\mathrm{AUC}(\mathrm{ng} \mathrm{h} / \mathrm{mL})$ & $1918 \pm 193$ & $194.1 \pm 74.2$ & $1047 \pm 654$ & $1664 \pm 1107$ \\
\hline $\mathrm{T}_{1 / 2}(\mathrm{~h})$ & $5.69 \pm 0.75$ & $5.65 \pm 2.81$ & $3.15 \pm 1.76$ & $4.08 \pm 1.43$ \\
\hline $\mathrm{V}_{\mathrm{ss}} / \mathrm{F}(\mathrm{mL} / \mathrm{kg})$ & $8.70 \pm 1.4$ & $8.0 \pm 5.7$ & $127 \pm 79$ & $207 \pm 107$ \\
\hline $\mathrm{CL} / \mathrm{F}(\mathrm{mL} / \mathrm{hr} / \mathrm{kg})$ & $1.05 \pm 0.1$ & $0.92 \pm 0.17$ & $29.0 \pm 10.4$ & $36.3 \pm 16.1$ \\
\hline $\mathrm{F}_{\text {absolute }}$ & - & $0.126 \%$ & $5.45 \%$ & $4.33 \%$ \\
\hline $\mathrm{F}_{\text {relative }}$ & - & - & $4.315 \%$ & $3.429 \%$ \\
\hline
\end{tabular}

Table 4: Pharmacokinetics of etravirine following intravenous administration of pure etravirine solution or oral administration of formulation \#59 versus the commercia Intelence ${ }^{\circledR}$ product to male SD rats. 


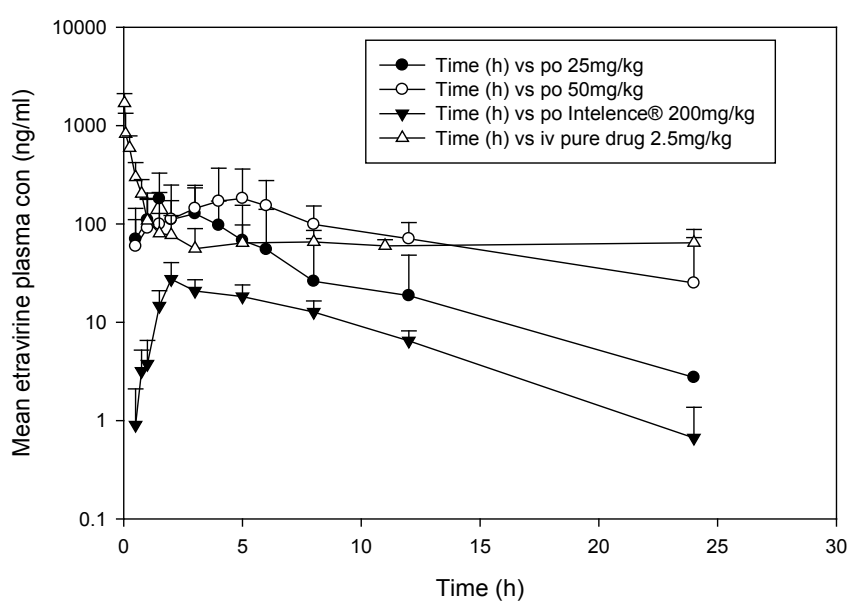

Figure 2: Mean $( \pm S D)$ comparative plasma etravirine concentration versus time profiles after oral administration of a $25 \mathrm{mg} / \mathrm{kg}$ or $50 \mathrm{mg} / \mathrm{kg}$ dose of our formulation \#59 or a $200 \mathrm{mg} / \mathrm{kg}$ dose of Intelence ${ }^{\circledR}$ to male Sprague-Dawley rats.

forFormulation \# 59 was $5.45 \%$ at $25 \mathrm{mg} / \mathrm{kg}$ dose and $4.33 \%$ at 50 $\mathrm{mg} / \mathrm{kg}$ dose. In other words, Formulation \# 59 is 34 to 43 -times more orally bioavailable as compared with the reference Intelence ${ }^{\circledR}$ tablet. Therefore, our formulation \# 59 has achieved as much as 43 -fold increase in the oral availability of the drug.

\section{Acute toxicity}

No signs of discomfort or any cardiovascular or respiratory disorders were observed in all animals after the drug administrations and throughout the study period. There was no change in body weight monitored for a 7-day period after drug administrations.

\section{Discussion}

Etravirine has been marketed as Intelence ${ }^{\circledR} 25,100$ and $200 \mathrm{mg}$ tablets for the treatment of HIV infection [1,3]. Etravirine is more effective than the first generation NNRTIs due to its activity against NNRTI-resistant HIV-1 [1]. In 2012, Intelence ${ }^{\circledR}$ was approved for use in pediatric patients from 6 to 18 years of age [12]. This makes etravirine the only NNRTI indicated for use in the pediatric and adult population who are resistant to NNRTIs and other antiretroviral medications. The recommended dose of this drug is $200 \mathrm{mg}$ taken twice daily following a meal for adults and 100-200 mg based on body weight in pediatric population [3]. Etravirine is a class IV compound according to the biopharmaceutics classification system, i.e., low water solubility and low gastrointestinal permeability [13]. Despite its use in the clinical management of HIV-infected patients, the drug has very limited bioavailability due to low aqueous solubility. There is a real need to introduce an oral liquid dosage formulation of etravirine for all populations including young AIDS patients from 6 years of age, who are often unable to swallow multiple tablets and for those who need a dose modification due to hepatic or renal impairment. Also, there is a necessity to develop a more bioavailable formulation of etravirine for better clinical outcomes. We formulated a unique cosolvent formulation of etravirine suitable for oral administration with over 40 -fold oral availability compared to the commercially available tablet form. The formulation contains $5 \mathrm{mg} / \mathrm{mL}$ of etravirine dissolved in 3.5\% 1-methyle 2 -pyrrolidinone, $46.5 \%$ Labrasol, and $50 \%$ water. The formulation was found to be stable after 3 months storage at room temperature. The drug formulation was successfully administered to rats without any signs of acute toxicity.

There have been several attempts to increase the bioavailability of poorly water-soluble drugs by the cosolvent approach to improve its solubility and bioavailability [14-17]. Yeh et al. [16] attempted a cosolvent formulation where they improved the bioavailability and solubility characteristics of Tenoxicam. To overcome the challenges in drug delivery, we successfully developed a co-solvent formulation of etravirine suitable for oral administration. The increase in bioavailability could be due to the potential increase in etravirine penetration through the gastrointestinal mucosa in presence of NMP and Labrasol. This is confirmed by an up to 20 fold increase in $\mathrm{Vd}$ of cosolvent formulations in comparison to the commercial tablet dosage form. NMP is a proven chemical penetration enhancer [18] and helps to increase the permeability of both hydrophilic and hydrophobic drugs [19]. It is widely used as a penetration enhancer in the commercially available formulations such as griseofulvin, insulin, fluoxetine and ibuprofen [18]. Labrasol is also reported as a penetration enhancer [20]. Moreover, Labrasol is a safe and non-ionic surfactant which helps in the solubilization of water insoluble drugs through an emulsification process. It is also reported that it enhances the oral bioavailability of hydrophobic drugs like diclofenac diethylamide [21]. The increase in bioavailability may be attributed to the improved solubility of etravirine in NMP. This is also supported by the fact that the mean plasma concentration of etravirine was significantly higher for the formulation $(25 \mathrm{mg} / \mathrm{kg}$ and $50 \mathrm{mg} / \mathrm{kg}$ ) compared to the marketed tablet $(200 \mathrm{mg} / \mathrm{kg})$ throughout the entire sampling time.

Figure 2 shows a sustained plasma level of etravirine from the cosolvent formulation in both doses administered. This could be due to the fact that after oral administration, NMP diffuses away from the site because of its water miscibility and etravirine precipitates out and acts as a depot at the site making the absorption slower compared to its elimination. Similarly, it has been reported previously that an Atrigel delivery system containing NMP developed by Atrix Lab is used for both dental mucosal treatment and parenteral administration [21]. Our cosolvent formulation provided a significantly higher $C_{\max }$ of 8 -fold increase and 5-fold increase in the Area Underthe Curve (AUC) for $25 \mathrm{mg} / \mathrm{kg}$ as compared with commercial Intelence ${ }^{\circledR}$ group. Interestingly, there was no significant difference between the $\mathrm{C}_{\max }$ of 25 $\mathrm{mg} / \mathrm{kg}$ and $50 \mathrm{mg} / \mathrm{kg}$ doses of our cosolvent formulation. This suggests a saturation of absorption process with an increase in dose. The $\mathrm{T}_{\max }$ for our formulation $(25 \mathrm{mg} / \mathrm{kg})$ and the commercial tablet were similar ( 2 hours) whereas it was delayed (5 hours) for higher dose $(50 \mathrm{mg} / \mathrm{kg}$ ) of our cosolvent formulation. This effect on $\mathrm{T}_{\max }$ could be due to the etravirine interaction with cosolvent system at higher concentration and delayed the time to achieve maximum plasma concentration [16]. Moreover, a change in the absorption kinetics at higher drug concentration in the GI tract could also be the reason for this effect. The $\mathrm{T}_{\max }$ was attained slowly in the cosolvent formulation compared to the marketed formulation ensuring that there was no burst release of etravirine. The increase in bioavailability is mainly attributed to the dramatic increase in the solubility of etravirine in NMP compared to other solvent in the presence of $50 \%$ water.

The major obstacles to effective etravirine therapy are (1) poor aqueous solubility (2) limited bioavailability (3) poor patient compliance. Oral liquid dosage forms offer several advantages compared to solid dosage forms. They increase the bioavailability of poorly water soluble compounds, offer better patient compliance, offergreat flexibility in 
dosing especially in situations where dose adjustments in hepatic or renal impaired patients are required, and it is an ideal formulation for patients who cannot swallow tablets or capsules. Currently, there are several anti HIV oral liquid formulations commercially available. For example, a combination product of lopinavir and ritonavir as an oral solution (Kaletra ${ }^{\circledR}$, Abbvie) and ritonavir oral solution (Norvir ${ }^{\circledR}$, Abbott) are cosolvent oral formulation systems that are currently available for HIV treatment. Hence, an oral liquid formulation of etravirine would be a logical addition to the list of agents available for HIV therapy.

The market share of etravirine significantly increased as it was approved recently (2012) for use in children from 6 years of age and adults [12]. Currently, all the available dosage forms of etravirine are solid dosage forms which make it a perfect candidate for a liquid formulation. Hence, there is a great need to improve patient compliance by providing more choices in dosage forms. Recent studies have demonstrated the uniqueness of cosolvent formulations. For example, Yeh et al. [16] reported that cosolvent formulations have following advantages over other forms such as (1) ease of direct administration without reconstituting the powder form (2) better safety profile as contamination while reconstitution can be avoided (3) economical, as complex pharmaceutical technologies are not necessary (4) simple and easy to formulate. The commonly used cosolvents in pharmaceutical formulations are polyethylene glycol, ethanol, bile salts, NMP, dimethyl acetamide and polysorbates [22]. Our formulation is a water soluble and stable etravirine liquid dosage formulation that is suitable for oral administration.

Among the various mediums tried in our laboratory, a cosolvent system was chosen consisting of NMP, Labrasol, and water at 3.5:46.5:50 (v/v/v) ratios showed $5 \mathrm{mg} / \mathrm{mL}$ drug solubility in $50 \%$ of an aqueous medium and no drug precipitation after storage. Thus, this formulation was selected for further long-term drug stability testing as well as in vivo bioavailability evaluations. NMP is one of the major pharmaceutical cosolvents with strong solubilizing properties and is widely used in oral and parenteral formulations. NMP is a water miscible polar aprotic solvent with high interfacial activity as a drug solubilizer and a penetration enhancer and used in concentrations up to $60 \%$ [19]. NMP is a biodegradable solubilizing agent with high safety profile. It is a clear to slightly yellow liquid miscible with water and solvents like ethyl acetate, chloroform, benzene and lower alcohols or ketones. It also belongs to the class of dipolar aprotic solvents which includes dimethylformamide, dimethylacetamide and dimethyl sulfoxide. Other names for this compound are: 1-methyl-2pyrrolidone, $\mathrm{N}$-methyl-2-pyrrolidinone, $\mathrm{m}$-pyrrole, and pharmasolve. The solubility enhancement of NMP is attributed to its ability to function as a cosolvent and complexing agent simultaneously. The non-polar carbons in NMP weaken the hydrogen bonding in water molecule. Also, it is possible that the large non polar region creates a hydrophobic interaction between NMP and etravirine [18]. These characteristics of NMP allowed the highest solubility of etravirine. The cosolvent approach is based on the fact that low aqueous solubility of drugs is due to great difference in polarity of the two components. Thus when a cosolvent having a polarity value less than that of water is added, the polarity difference between the drug and the water-co solvent system reduces thereby increase the solubility of drug [22].

Based on in vitro experiments, etravirine is thought to be absorbed via a passive transcellular diffusion mechanism. Moreover, etravirine is an inhibitor of p-gp with an apparent $\mathrm{IC}_{50}$ value of $24.2 \mu \mathrm{M}$. Etravirine is absorbed slowly, with median peak concentration occurring at approximately 4.0 hours ( 2 to 6 hours depending on the formulation) after fasted oral administration. The absolute bioavailability of etravirine has not been determined because of the lack of an intravenous formulation [6]. In vivo, etravirine is an inducer of CYP3A4 and an inhibitor of the CYP2C subfamily [7,23]. Etravirine has a terminal elimination half-life in plasma of approximately 30-40 h. The drug should be taken following a meal to enhance bioavailability [8]. We believe that co-solvent liquid formulation of etravirine is suitable for further development and have potential clinical applications.

\section{Conclusion}

We have developed a co-solvent formulation of etravirine suitable for oral administration. The formulation contains $5 \mathrm{mg} /$ $\mathrm{mL}$ of etravirine dissolved in 3.5\% 1-methyle 2-pyrrolidinone, $46.5 \%$ Labrasol, and $50 \%$ water. The formulation was found to be stable after 21 months of storage at room temperature. The drug formulation was successfully administered to rats without any signs of acute toxicity. Pharmacokinetic study showed an over 40 times superior oral bioavailability of our formulation as compared with the marketed Intelence ${ }^{\circledR}$ Tablet formulation.

\section{Author Contribution}

Jyothy John performed experiments and wrote manuscript;Dong LIANG designed experiments and wrote manuscript.

\section{References}

1. Johnson LB, Saravolatz LD (2009) Etravirine, a next-generation nonnucleoside reverse-transcriptase inhibitor. Clin Infect Dis 48: 1123-1128.

2. Adams J, Patel N, Mankaryous N, Tadros M, Miller CD (2010) Nonnucleoside reverse transcriptase inhibitor resistance and the role of the second-generation agents. Ann Pharmacother 44: 157-165

3. (2013) INTELENCE ${ }^{\circledR}$ (etravirine) Tablets Package Insert.

4. Schöller-Gyüre M, Kakuda TN, Raoof A, De Smedt G, Hoetelmans RM (2009) Clinical pharmacokinetics and pharmacodynamics of etravirine. Clin Pharmacokinet 48: 561-574.

5. Crauwels HM, Kakuda TN (2010) Drug interactions with new and investigational antiretrovirals. Clin Pharmacokinet 49: 67-68.

6. (2008) CHMP Assessment Report for INTELENCE. Evaluation of Medicines for Human Use.European Medicines Agency.

7. Kakuda TN, Scholler-Gyure M, Woodfall BJ, De Smedt G, Peeters M, et al (2006) TMC125 in combination with other medications: summary of drug-drug interactions. Proceedings of the 8th International Congress on Drug Therapy in HIV Infection, Glasgow, Scotland.

8. Scholler-Gyure M, Leemans R, Vyncke V, Vandermeulen $K$, Peeters $M$, Baeten B, et al. (2006) Effect of food on the oral bioavailability of the phase III formulation of TMC125. Proceeding of the 7th International Workshop of Clinical Pharmacology, Lisbon, Portugal.

9. Amidon GL, Lennernäs H, Shah VP, Crison JR (1995) A theoretical basis for a biopharmaceutic drug classification: the correlation of in vitro drug product dissolution and in vivo bioavailability. Pharm Res 12: 413-420.

10. Schöller-Gyüre M, Kakuda TN, Raoof A, De Smedt G, Hoetelmans RM (2009) Clinical pharmacokinetics and pharmacodynamics of etravirine. Clin Pharmacokinet 48: 561-574.

11. Abobo CV, Wu L, John J, Joseph MK, Bates TR, et al. (2010) LC-MS/MS determination of etravirine in rat plasma and its application in pharmacokinetic studies. J Chromatogr B Analyt Technol Biomed Life Sci 878: 3181-3186.

12. Osterholzer D (2013) The role of etravirine in the management of treatmentexperienced pediatric patients with HIV. HIV AIDS (AuckI) 5: 67-73.

13. Usach I, Melis V, Peris JE (2013) Non-nucleoside reverse transcriptase inhibitors: a review on pharmacokinetics, pharmacodynamics, safety and tolerability. J Int AIDS Soc 16: 1-14. 
Citation: John J, Liang D (2014) Oral Liquid Formulation of Etravirine for Enhanced Bioavailability. J Bioequiv Availab 6: 046-052. doi:10.4172/ jbb.1000179

14. Sun M, Si L, Zhai X, Fan Z, Ma Y, et al. (2011) The influence of co-solvents on the stability and bioavailability of rapamycin formulated in self-microemulsifying drug delivery systems. Drug Dev Ind Pharm 37: 986-994.

15. Bittner B, Thelly T, Isel H, Mountfield RJ (2000) The impact of co-solvents and the composition of experimental formulations on the pump rate of the ALZET osmotic pump. Int J Pharm 205: 195-198.

16. Yeh MK, Chang LC, Chiou AH (2009) Improving tenoxicam solubility and bioavailability by cosolvent system. AAPS Pharm Sci Tech 10: 166-171.

17. Chu Z, Chen JS, Liau CT, Wang HM, Lin YC, et al. (2008) Oral bioavailability of a novel paclitaxel formulation (Genetaxyl) administered with cyclosporin A in cancer patients. Anticancer Drugs 19: 275-281.

18. Saw CL, Olivo M, Wohland T, Fu CY, Kho KW, et al. (2007) Effects of N-methy pyrrolidone on the uptake of hypericin in human bladder carcinoma and co- staining with DAPI investigated by confocal microscopy. Technol Cancer Res Treat 6: 383-394.

19. Jouyban A, Fakhree MA, Shayanfar A (2010) Review of pharmaceutical applications of N-methyl-2-pyrrolidone. J Pharm Pharm Sci 13: 524-535.

20. Koga K, Kusawake Y, Ito Y, Sugioka N, Shibata N, et al. (2006) Enhancing mechanism of Labrasol on intestinal membrane permeability of the hydrophilic drug gentamicin sulfate. Eur J Pharm Biopharm 64: 82-91.

21. Strickley RG (2004) Solubilizing excipients in oral and injectable formulations Pharm Res 21: 201-230.

22. Gupta PK (2005) Solutions and phase equilibria. Remington: The Science and Practice of Pharmacy (21st edition) Philadelphia, USA.

23. John J, John M, Wu L, Hsiao C, Abobo CV, et al. (2013) Effects of etravirine on the pharmacokinetics and pharmacodynamics of warfarin in rats. $\mathrm{Br} J$ Pharmacol 168: 1851-1858. 